\title{
Malignant esophagobronchial fistula with severe esophageal stenosis, successfully treated by trans- bronchial occlusion with cyanoacrylate glue
}
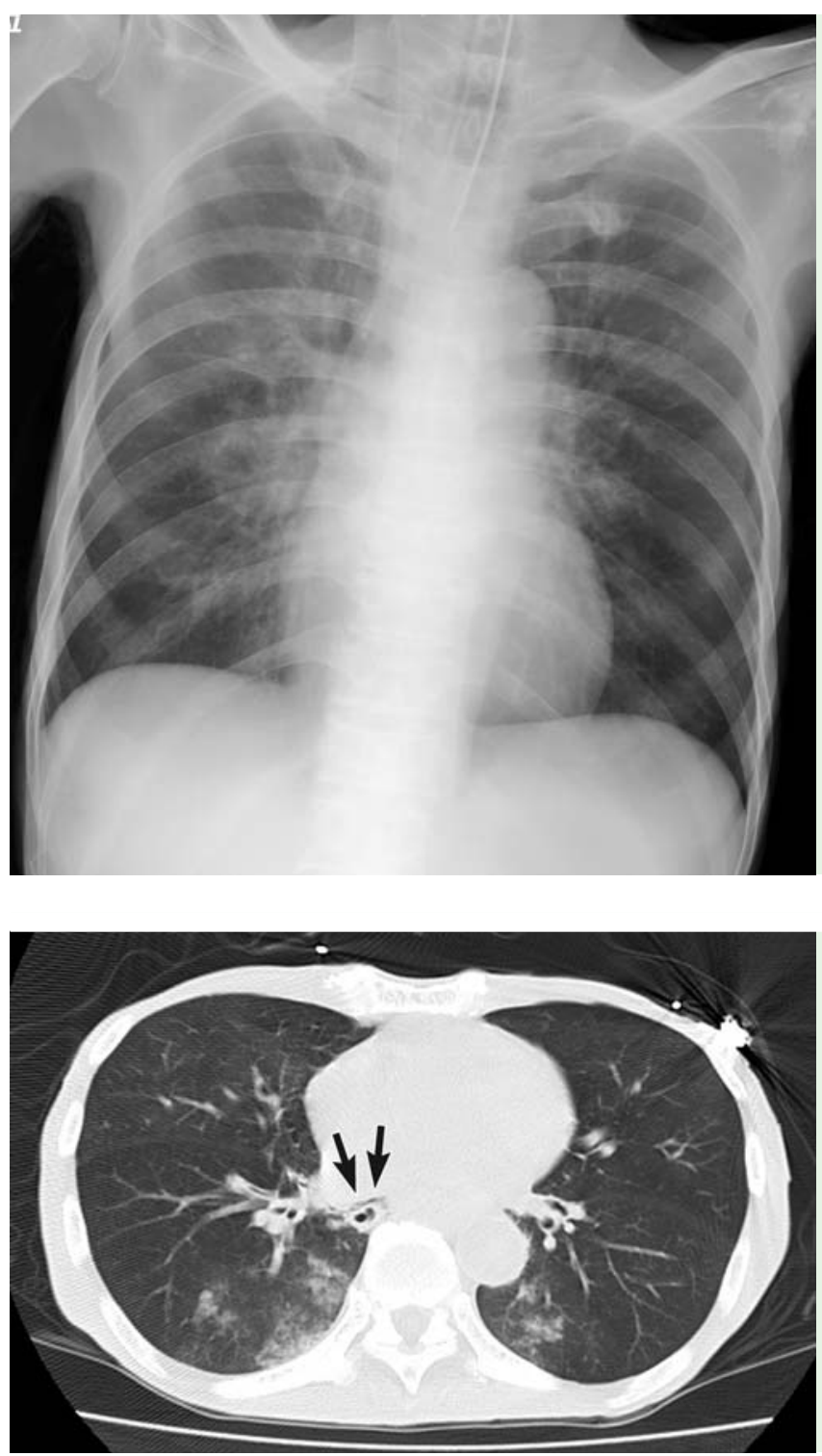

Fig. 2 Chest computed tomography (CT) demonstrating a small cavitary lesion (arrows) in the apical region of the right lower lobe of the lung, next to the esophageal tumor. This cavitary lesion is a part of an esophagobronchial fistula due to necrotizing rupture of esophageal cancer by chemotherapy.

A 68-year-old man with advanced esophageal cancer was receiving chemotherapy. On day 6 , he suddenly complained of massive greenish-black watery sputa that looked like stomach contents. A chest radiograph showed right hilar infiltration ( $\bullet$ Fig. 1). Chest computed tomography (CT) demonstrated a small cavitary lesion next to the esophageal tumor ( $\mathbf{F i g . 2}$ ). The patient soon fell into respiratory failure and needed artificial respiration. Bronchoscopy showed massive black sputa, continuously coming up from the right B6a bronchus. Malignant esophago- bronchial fistula due to necrotizing perforation of the esophageal cancer following chemotherapy was then diagnosed.

The esophagus had been severely stenosed, and endoesophageal stenting seemed difficult. Thus, endobronchial closure was attempted. A $1.7-\mathrm{mm} / 5-\mathrm{Fr}$, 210-cm, ultra-tapered-tip catheter for endoscopic retrograde cholangiopancreatography (Contour ERCP cannula; Boston Scientific Japan, Tokyo, Japan) that had been filled with distilled water was inserted into the right $\mathrm{B} 6 \mathrm{a}$ bronchus by a flexible video bronchoscope (Olympus

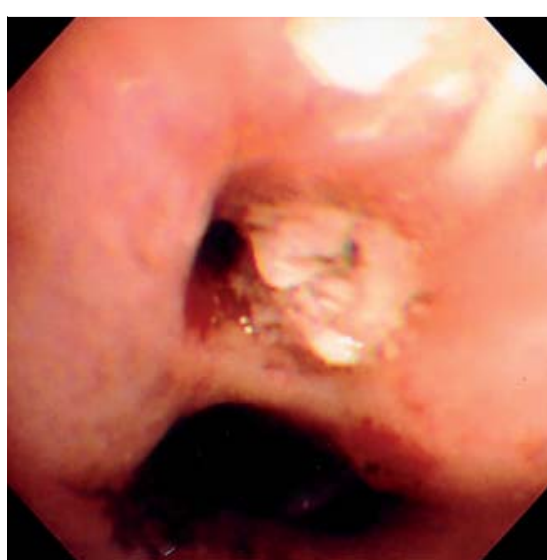

Fig. 3 Bronchoscopy demonstrating total closure of the right B6a bronchus with a hardened mixture of cyanoacrylate glue and Lipiodol.

EVIS BF-P240; Olympus, Tokyo, Japan). A mixture of $1.5 \mathrm{~mL}$ of cyanoacrylate glue (Alon Alpha A; Toa Gosei, Tokyo, Japan) and $1.5 \mathrm{~mL}$ of Lipiodol was rapidly injected into the catheter and then flushed with $10 \mathrm{~mL}$ of air. Just after the injection, the orifice of B6a was completely occluded by the hardened mixture, and the leak of black sputa was completely stopped ( Fig.3). Distribution of Lipiodol in the right S6a segment was demonstrated on a chest radiograph ( Fig.4). Chest CT also visualized the S6a area filled with Lipiodol, including the cavitary lesion (๑ Fig.5).

The patient was successfully released from artificial respiration on day 7 following endobronchial occlusion, without any respiratory complications. On day 8 , bronchoscopy confirmed closure of the right B6a bronchus. On day 14, upper gastrointestinal series demonstrated relief from esophageal stenosis, without any evidence of a communicating fistula from the esophagus to the bronchus. Enteral nutrition via a nasogastric tube was then started, and the patient's systemic status was dramatically improved. On day 21, chest CT confirmed no pulmonary infiltration in the right S6 area or reopening of the fistula.

Malignant esophagobronchial fistula is a critical condition and difficult to manage. Recently, various studies report endoesophageal stenting being widely used to 


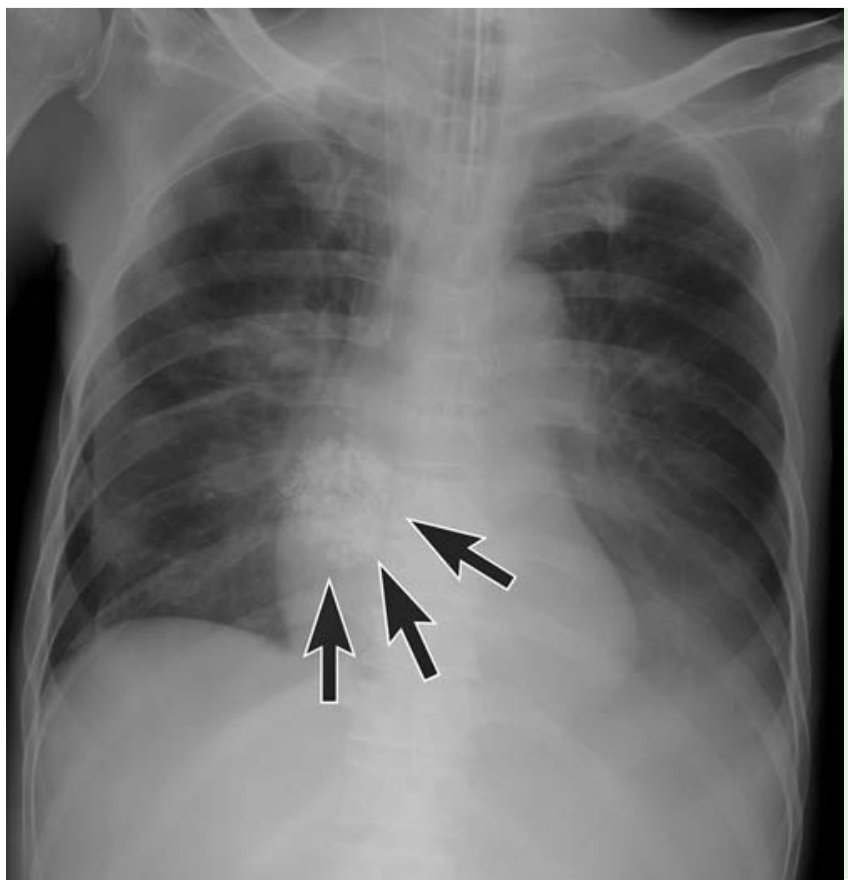

Fig. 4 Chest radiograph (the contrast has been changed) demonstrating distribution of Lipiodol in the medial region (S6a) of the apical segment of the right lower lobe of the lung (arrows).

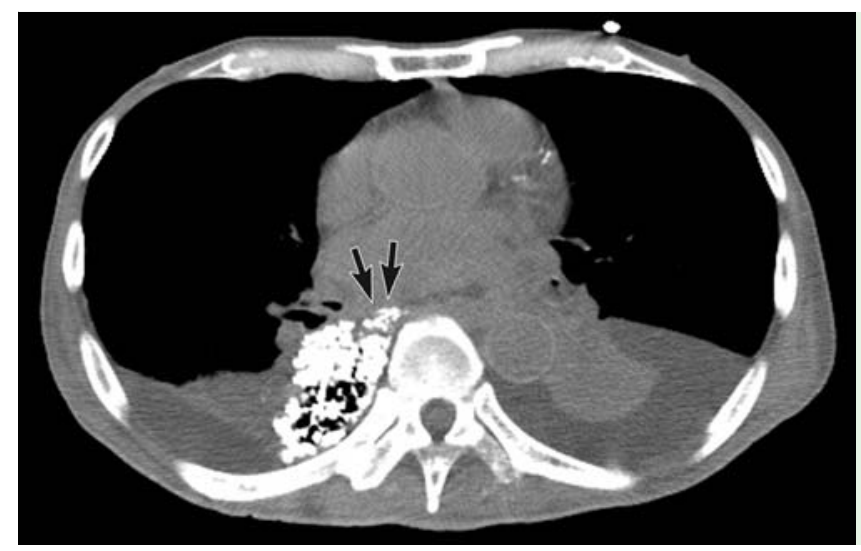

Fig. 5 Chest computed tomography (CT) showing the medial region (S6a) of the apical segment of the right lower lobe and cavitary lesion (arrows) filled with Lipiodol. The Lipiodol-filled cavitary lesion seems to communicate with the lumen of the esophagus. Partial atelectasis of the superior (S6b) and lateral (S6c) regions is also seen.

close the fistula because that gives better quality of life [1]. However, with severe, complicated esophageal stenosis, an endoesophageal procedure is sometimes difficult. Endobronchial occlusion may be a choice in such cases; its use has been reported [2]. Endoesophageal application of cyanoacrylate glue is reported for closure of benign esophagobronchial fistulae [3, 4]. Also, we have previously reported safe usage of cyanoacrylate glue for endobronchial closure of malignant bronchopleural fistula [5]. We believe this is the first report of endobronchial occlusion of malignant esophagobronchial fistula with cyanoacrylate glue.

\section{Endoscopy_UCTN_Code_TTT_1AO_2AI}

Competing interests: None
T. Iwata ${ }^{1,}$, K. Chung1, M. Toda ${ }^{2}$,

A. Hiraoka², H. Hagiwara², S. Hanada ${ }^{1}$, T. Yokota ${ }^{1}$, K. Inoue ${ }^{1}$, T. Miura ${ }^{1}$

${ }^{1}$ Department of Thoracic and Cardiovascular Surgery, Kansai Rosai Hospital, Japan

2 Department of Digestive Medicine, Kansai Rosai Hospital, Japan

\section{References}

$1 \mathrm{Hu} Y$, Zhao YF, Chen LQ et al. Comparative study of different treatments for malignant tracheoesophageal/bronchoesophageal fistulae. Dis Esophagus 2009; 22: 526-531

2 Miwa K, Mitsuoka M, Tayama $K$ et al. Successful airway stenting using silicone prosthesis for esophagobronchial fistula. Chest 2002; 122: 1485-1487

3 Yellapu RK, Gorthi JR, Kiranmayi $Y$ et al. Endoscopic occlusion of idiopathic benign esophago-bronchial fistula. J Postgrad Med 2010; 56: 284-286

4 Barthelemy C, Audigier JC, Fraisse H. A nontumoral esophago-bronchial fistula managed by isobutyl-2-cyanoacrylate. Endoscopy 1983; 15: 357-358

5 Iwata T, Iida S, Hanada $S$ et al. Transbronchial occlusion of a malignant bronchopleural fistula with cyanoacrylate glue. J Bronchol Intervent Pulmonol 2011; 18: 176-178

\section{Bibliography}

DOI http://dx.doi.org/

10.1055/s-0032-1309849

Endoscopy 2012; 44: E317-E318

(c) Georg Thieme Verlag KC

Stuttgart · New York

ISSN 0013-726X

\section{Corresponding author}

\section{T. Iwata, MD, PhD}

Department of Thoracic and Cardiovascular Surgery

Kansai Rosai Hospital

3-1-69 Inabaso

Amagasaki

Hyogo 650-8511

Japan

Fax: +81-6-6419-1870

taiwata@med.osaka-cu.ac.jp 